\title{
The Adoption of Formal HRM Practices by Small Firms in Africa
}

\section{Franca Ovadje}

\section{Introduction}

Several studies in the extant literature indicate that there is a significant relationship between Human Resource Management (HRM) practices and firm performance (Arthur, 1994; MacDuffie, 1995; Huselid, 1995; Guest et al. 2003). Huselid (1995) found that investments in high performance work systems were associated with greater productivity and corporate financial performance. The study by Guest et al. (2003) suggests a "positive association between the use of more HR practices and lower labour turnover and higher profitability". Although a large majority of the studies were carried out in large companies, some support has been found for a positive association between HRM practices and performance in small and medium sized firms (Kotey \& Slade, 2005).

Small and medium sized firms (SMEs) are vital to a nation's economy (Heneman, et al. 2000; Ariyo, 2005); they produce a high proportion of national output and provide an even greater proportion of employment (Foreman-Peck et al., 2006). Past research on small firms in Africa suggests that few small firms grow. Onyiewu, (1993) found in his study of small firms in Eastern Nigeria that the few small businesses which grew, adopted innovative management systems. Their owners were exposed to new ideas; they employed qualified people and created a formal management system - including a people management system.

Not much is known about why SMEs in Africa adopt, or fail to adopt formal HRM practices. An investigation of the role of HRM in small firms should unearth the people management practices SMEs adopt, when and why they adopt them, as well as, what effect these have on performance.

Past research on SMEs has been focused on macro level factors which affect SME performance including infrastructural constraints, lack of access to technology, and so on. Mambula (2002) investigated the reasons for the stagnation of SMEs in Nigeria. While the consultants he interviewed blamed the poor performance of SMEs on infrastructural constraints, poor support services and incentives by the government, the government officials and the development bankers on the other hand emphasized the lack of organization and training of the entrepreneurs themselves. An investigation of the micro level factors is necessary to unearth the internal constraints which impede SME growth in Africa. One of these factors is HRM practices.

The rest of the paper is structured thus: The following section is a review of existing literature on the reasons why SMEs adopt formal HRM practices. We also derive some hypotheses. We show how personal and organizational factors that relate directly to the attainment of organizational objectives affect the decision to adopt formal HRM practices. We also argue that the institutional environment affects SMEs differently than large firms. Finally, we summarize the discussion and draw some implications. 


\section{Determinants of the Adoption of Formal HRM Practices by SMEs}

SMEs vary in size and complexity. It is therefore not surprising that there is no generally accepted definition of SMEs. Newberry (2006) suggests that the most general definition of an SME in emerging economies is a company employing between 10 and 100 people.

The extent of formalization and the intensity of HRM practice in SMEs are likely to differ from what obtains in larger firms. The reasons are probably obvious. SMEs typically have fewer employees so that the level of interaction among them may be higher than in larger firms. CEOs/founders maintain a close relationship with their employees and often perform the role of personnel managers. In essence, small firms are often characterized by informality not only in relationships amongst employees and with the CEO, but also in systems, structures and practices, including people management practices. However, several other factors motivate the adoption of formal HRM systems. The assumption of informality may not always hold or there may be various levels of formality as well as differences in the practices SMEs adopt.

\section{Personal Factors and the Adoption of formal HRM Practices}

The decision to adopt HRM practices may be due to external and internal factors. The internal factors may be personal and organizational. Past research suggests that the CEO/founder's orientation affects the decision to adopt HRM practices (Wager, 1998). CEO/founder orientation is itself influenced by education, formal training, previous experience in formal settings, etc. These provide the founder with knowledge of formal HRM practices.

This knowledge may also be provided by consultants, entrepreneurship support services, business schools, etc. Through these media, the CEO/founder and the senior management team become aware and convinced of the need for formal HRM practices. Those CEO/founders who have experience working in formal settings (usually large organizations with systems and processes including HRM practices) are likely to adopt similar practices when they set up their own businesses. The formal setting exposes the founder to the benefits of HRM practices for employee morale, employee retention, and organizational performance. Personal experience in a formal setting is perhaps the most important factor influencing the decision to adopt HRM practices.

Personal experience and exposure to formal HRM practices is particularly important because the benefits of HRM practices are often not clear at the time of adoption. There is usually a time lag between implementation of formal HRM practices and when the results or benefits become visible. Besides, SMEs have limited resources. They are more likely to invest in HRM practices if they have experienced the benefits themselves or are convinced by significant others of the benefits of these practices. On the other hand, the costs of implementing these practices are upfront and often substantial for a small firm. In a longitudinal study of 37 micro and small scale enterprises in Nigeria, Onyeiwu (1993) found that companies that survived shared some common characteristics. Their owners had some education and had been exposed to formal management systems. Thus:

Proposition 1: CEO/founders who have experience in formal settings, and who have had access to knowledge about formal HRM practices through consultants or training programmes are more likely to adopt formal HRM practices 


\section{Organizational Factors and the Adoption of HRM Practices}

The decision to adopt formal HRM practices depends on the perceived link between the organizational strategy and people management. If people are perceived to be critical to the attainment of strategic objectives, formal HRM practices are likely to be adopted. Duberly and Walley (1995) found in their study of SMEs in UK manufacturing that management perception of how to succeed in a highly competitive environment influenced the adoption of HRM practices. Companies that viewed employees as sources of competitive advantage tended to adopt these practices while those that focused on cost reduction strategies did not.

Bacon and Hoque (2005) found that the strongest predictor of adoption of formal HRM practices by SMEs is the skills-mix of the workforce. SMEs have difficulty attracting, motivating and retaining key staff. Yet, without people with the necessary expertise, the organization cannot achieve its objectives. Subramony (2006) cites Boudreau and Ramstad (2003) who argued that HRM practices are of greatest utility if applied to jobs which are critical for strategy implementation. Thus, SMEs in which the skills-mix is dominated by highly skilled workers are more likely to adopt formal HRM practices. Conversely, firms in which a large majority of employees need basic knowledge and skills are less likely to adopt HRM practices. Thus:

Proposition 2: SMEs that employ a highly skilled workforce are more likely to adopt formal HRM practices

\section{Organizational Life Cycle and Adoption of formal HRM Practices}

Organizations have a life cycle; they are born, they grow, mature and, unless they are rejuvenated, they decline. As they move along these developmental stages, many changes take place in the internal and external environment of the firm. Organizations therefore face different problems as they grow and age. These changes may render the organization's established processes of self maintenance ineffective and this may lead to the demise of the organization (Kaufman, 1975).

The ability to adapt as the firm moves along the Organizational Life Cycle (OLC) is critical for the survival and growth of the firm. Movement along the OLC is a major determinant of the adoption of formal HRM practices by SMEs. If new challenges are not overcome, the organization may become out of sync with its environment. This may result in lower levels of efficiency and effectiveness (Baird and Meshoulam, 1988).

A basic proposition that arises from the foregoing is that formal HRM practices will vary over the life-cycle of the firm. Rutherford et al. (2003) found some support for this proposition in their study of 2,903 family businesses. They examined specific HR problems within the context of the age, size and growth stage (measured by level of sales growth achieved) of the firm and concluded that as firms achieve increasing levels of growth, HR issues seem to shift from attracting to retaining to training. The formal HRM practices that will be adopted to solve the HR problems will vary over the life-cycle.

At the birth stage the major challenges are finding a niche in the market, acquiring needed resources and hiring people. At this stage, the relationship between the founder and the organization is nearly isomorphic (Heneman and Tansky, 2002). The CEO feels able to cope 
with running the enterprise as the level of complexity is low. The founder/CEO often hires from informal channels and social networks (Carroll et al. 1999 cited in Kotey \& Slade, (2005)).There is no clear organizational structure; job descriptions are fluid; employees are expected to do what it takes to make the company successful. New hires negotiate compensation packages. Little or no employment tests are done during hiring. The firm is small and the founder has a one-on-one relationship with all the employees. He or she sees no need for formal, sophisticated HRM practices; the business need for them is not clear at this stage. The people challenge at the birth stage is reduced to attraction, that is, recruitment and hiring (Rutherford et al. 2003).

Proposition 3a: Few formal HRM practices will be adopted at the birth stage of the OLC.

As the firm grows, the founder and the organization become increasingly less intertwined. Growth brings increased complexity and new challenges. Problems of coordination and control soon arise. There are increasing demands on the founder/CEOs time and knowledge. More people with new skills are required. The social network as a source of qualified candidates becomes inadequate at this stage; a wider business network is needed to attract better qualified people into key positions. More sophisticated hiring techniques and procedures may be introduced at this stage. Consultants, interview panels, referees, etc. are often used in the growth stage of the firm.

As new employees are hired, complaints about inequity among older members of staff arise due to the lack of a compensation structure. Another challenge the firm faces at this stage is that of lack of skills among the older members of staff. While the social network was a source of loyal staff, these employees may not have the skills to operate in the new environment. People problems begin to take up a lot of the CEO's time.

To overcome the challenges of the growth stage, more HRM practices are adopted. Decentralization of decision making, functional specialization and the introduction of systems are likely to be adopted during the growth stage (Scott, cited in Quinn and Cameron, 1983). Formal compensation structures and managerial development systems may also be introduced. Heneman and Tansky (2002) noted that there is increasing institutionalization and delegation of HRM as the firm grows. The role of managing the relationship with employees is likely to be assigned to a person or a department during the growth stage. Kotey \& Slade (2005) found that SMEs move in the direction of more enunciated and prescribed practices as they grow in size. Thus:

Proposition 3b: A full range of formal HRM practices is likely to be adopted at the growth stage

As the company matures, predictability and coordination become very important (Downs, quoted in Quinn and Cameron, 1983). This is also the maintenance and refinement stage. According to Baird and Meshoulam (1988), job evaluation, labour relations and a broader role for HRM practices are the adopted at the maturity stage.

Proposition 3c: At the maturity stage, formal HRM practices are refined and maintained.

So far, we have assumed that the adoption of HRM practices by small firms is the result of 
rational choices made by the leaders of these firms. However, adoption may be the result of nonrational forces (Subramony, 2006). In the following section, we discuss the impact of the institutional environment on the adoption of formal HRM practices by SMEs. We conclude that context matters.

\section{The Institutional Environment and the Adoption of formal HRM Practices by SMEs}

Existing HRM models assume that decision-making in organizations is guided by a strategic logic; that firms adopt formal HRM practices in order to attain well-defined strategic goals (e.g. Miles \& Snow, 1984). However, this logic is unlikely to fully explain the adoption of formal HRM by SMEs. Institutional theory provides a framework for understanding the 'non-rational' drivers of the adoption of formal HRM practices in small firms (Harney \& Dundon, 2006; Pauuwe \& Boselie, 2003; Boselie et al. 2003). In this section, we discuss the institutional pressures at the societal and organizational levels that influence the decision to adopt HRM practices. We conclude that SMEs in Africa may not feel the pressures at the societal levels as much as those at the level of the organizational field.

\section{Institutional Pressures at the Societal Level}

At the societal level, certain regulative and coercive institutions define what is possible, acceptable and legitimate (Judge et al, 2008). The laws of a country define what is legitimate in that country. Laws are enacted to guide or even shape behaviour (Judge et al. 2008). Regulatory mechanisms are aimed at ensuring that similar standards obtain across different firms. Organizations must confirm to these regulations if they are to continue in existence and be considered legitimate.

However, law enforcement is necessary if an institutional context is to be created. Where enforcement mechanisms are underdeveloped as in many African countries, there is little or not pressure to conform to the laws and regulations of the state. If the legal system and law enforcement mechanisms are well developed, isomorphic pressures (pressures to conform and thus be similar to other organizations) are likely to be significant and practices among firms will be similar. Thus, SMEs in economies where legal and regulatory mechanisms are effective are likely to have similar adopt stipulated practices.

In contrast, where institutional structures are underdeveloped, the pressure to conform is not felt. Not surprisingly, SMEs are often not the primary focus of state regulation and where such regulation exists, enforcement is weak (Kauffman, 2005). Newberry (2006) argued that SMEs face regulatory environments that are built to "solidify the dominance of large corporations in the formally regulated economy and incentivize entrepreneurs to operate informally, meaning illegally and out of government's regulatory reach”. For example, the Nigerian Pension Reform Act (2004) stipulates that firms employing more than five people establish a pension scheme for their employees. While there is no reliable data available on compliance, anecdotal evidence suggests that many small firms do not comply with the regulation. Law enforcement mechanisms

are not sufficient to identify, much less, prosecute offenders. SMEs will not feel an obligation to conform to regulatory and normative forces at the societal level. In other words, firms that do comply, do so for reasons other than legislation. Laws and regulations do not determine the adoption of formal HRM practices by SMEs. 
Proposition 4: Legal and regulatory pressures will not exert much influence on the decision to adopt formal HRM practices in African countries

\section{Institutional Pressures in the Organizational Field}

DiMaggio \& Powell (1983) define an organizational field as composed of 'organizations that, in the aggregate, constitute a recognized area of institutional life, including key suppliers, resource and product customers, regulatory agencies and other organizations that produce similar products or services' (e.g. an industry). Structural cohesion, as defined by the boundaries of the organizational field, permits the diffusion of similar practices within the field so that conformity could be a direct response to coercive mechanisms - for example larger firms with which SMEs do business or creditors, may stipulate that all SMEs doing business with them adopt certain practices (Zucker, 1977).

SMEs, like other firms, rely on the environment for customers, resources etc. One such resource is capital. Access to capital has been the bane of the growth of SMEs in developing countries (Albaladejo, 2002; Mambula, 2002). Some of the reasons that have been identified for this include: SMEs high risk profile - they are regarded by creditors and investors as high-risk borrowers due to insufficient assets and low capitalization as well as vulnerability to market fluctuations and high mortality rates. Information asymmetry arising from SMEs' lack of accounting records, inadequate financial statements or business plans, makes it difficult for creditors and investors to assess the creditworthiness of potential SME proposals. The providers of capital are likely to insist that SMEs comply with stringent requirements. One such requirement is the adoption of formal structures, practices and systems, including formal HRM practices. In order to attract capital, SMEs are likely to adopt practices and norms that signal to providers of capital that they are a profitable investment. Thus:

Proposition 5: SMEs are likely to adopt formal HRM practices in order to comply with stipulations of the providers of capital.

Another coercive pressure on SMEs in the organization field is that exerted by large firms within the field. The resource dependency perspective (Pfeffer \& Salancik, 1978) suggests that large organizations typically have more power and leverage over their environment than small firms. For example, a large firm in the food and beverage sector that needs a loan from a bank is more likely to exercise influence over the bank and obtain more favourable terms than a small firm in the same industry.

According to Scott \& Davis (2007), the size-based power of large firms insulates them from environmental pressures and puts them in a position of influence over competing firms. Many SMEs provide services to larger firms especially multi-nationals (Luetkenhorst, 2004). The latter often have contractual requirements that SMEs are expected to abide by and such requirements often have implications for the internal structure, processes and the people management practices that SMEs adopt. For example, SMEs providing services to oil companies in Nigeria are required to have sophisticated health and safety policies, training programmes, and so on for their employees. SMEs are likely to adopt the practices stipulated by the large companies they serve in 
order to gain acceptance and retain the business. Thus:

Proposition 6: SMEs which are a significant link in the value chain of larger companies are likely to adopt formal HRM practices if these are required by the large firm

According to DiMaggio \& Powell (1983), mimetic forces also drive isomorphism. Firms may adopt formal HRM practices to look similar to legitimate organizations. Mimetic isomorphism may be particularly important in emerging economies. Emerging economies are characterized by uncertainty (Utomi, 1997). In these environments, the probability of outcomes is often unknown because relevant information is lacking. Kamoche (1997) describes strategy in emerging economies as 'typically a combination of insightful planning and serendipity, the latter playing a much more significant role than observers might allow for.' In these environments, cause and effect relationships may not be clear. The pressure to imitate the actions of successful firms in the environment may be strong. This pressure will be more intense in national cultures characterized by a high level of uncertainty avoidance. SMEs are likely to mimic successful companies in their organizational fields. Thus:

Proposition 7: SMEs will adopt formal HRM practices of successful firms in the organizational field

In summary, we have tried to show that the decision to adopt formal HRM Practices is influenced by a number of factors: the life cycle stage of the organization, personal factors and institutional forces at the level of the organizational field. Which of these factors will exert the strongest influence on the decision to adopt formal HRM practices?

We have argued that while pressures at the societal level may not be an important determinant of adoption (a large majority of SMEs operate in the informal sector), isomorphic pressures within the organizational field are important in explaining adoption of HRM Practices by SMEs. Large firms may require those SMEs with whom they have a long term relationship to adopt systems, practices and processes including formal HRM practices. Banks and other significant creditors may also exert pressure on SMEs to adopt formal HRM practices. It is plausible that SMEs adopt these practices simply to comply with a requirement but nothing fundamental may change. That is SMEs may adopt these practices simply to signal to the creditors or key partners that they have met their requirements. They are therefore unlikely to enjoy the improvements in performance that should result from such adoption.

Onyeiwu (1993) found in his study of small firms in Nigeria that founders who were exposed to new ideas tended to adopt innovative management practices. This suggests that past experience and training of the entrepreneur is important for adoption. However, Mambula (2002) found that entrepreneurs were unwilling to attend training programmes to improve their competencies. He noted that the lack of entrepreneurial training is an impediment to SME development.

We contend that while personal factors are an important determinant of the adoption of formal HRM practices, few entrepreneurs have been exposed to these practices through training, past experience or mentorship. Since the benefits of adoption are not immediately felt, SMEs are 
unlikely to adopt HRM practices unless they have to.

Perhaps the most important determinant of the adoption of formal HRM practices is the stage in the organizational life cycle. SMEs are likely to adopt HRM practices at the growth stage. At this stage, the organization is more complex, the CEO/Founder finds he or she is unable to deal with the increasingly complexity and seeks solutions. If SMEs at the stage are exposed to formal HRM practices, they are likely to adopt them and truly implement them. SMEs in the growth stage, whose Founders/CEOs are not aware of the importance of formal HRM practices are unlikely to adopt them and therefore may not survive or at best may stagnate. SMEs that adopt formal HRM practices at the growth stage are more likely to survive and thrive.

\section{Discussion and Conclusion}

HRM is important for organizational performance. Past research results suggest that formal HRM practices are associated with firm performance. Several factors influence the decision by SMEs to adopt formal HRM practices. Some adopt them for rational reasons (after careful consideration of the costs and benefits of these practices). Others adopt formal HRM practices for non-rational reasons, for example, mimetic isomorphism.

The personal characteristics of the owner are important in the adoption decision. Owners with experience in formal settings for example are more likely to adopt HRM practices than others. We have argued that movement along the OLC is perhaps the most important reason why entrepreneurs adopt formal HRM practices. The quest for legitimacy and acceptance by significant stakeholders, also affects the decision to adopt these practices.

This paper contributes to the HRM research agenda. We explore the reasons why firms adopt formal HRM practices. In explaining the adoption of HRM and its impact on firm performance we bring together Organizational Life Cycle theory and Institutional Theory. By examining why and when small firms adopt formal HRM practices and which practices they adopt, we contribute to the body of knowledge about HRM in small firms.

\section{Implications}

This paper has some implications. We have argued that the adoption of HRM by SMEs is the result of a combination of isomorphic pulls, the stage on the organizational life cycle and personal characteristics.

This paper suggests that pressures for the adoption of formal HRM systems at the societal level may not be felt by SMEs in many African economies. This is because of the weak enforcement mechanisms in these environments. In African economies, pressures within the organizational field are more important for the decision to adopt formal HRM practices.

This paper also points to a need to expose entrepreneurs to the benefits of HRM. This can be done through training courses, opportunities to network with HRM managers, CEOs of large firms in their industry, or professional associations. Given the low level of Business Development Services available to SMEs in Africa, policies that strengthen the capacity of institutions to provide these services, especially training for entrepreneurs, will go a long way 
towards exposing SMEs to HRM practices and thus increasing the adoption of these practices.

\section{References}

Albaladejo, M. (2002). Promoting SMEs in Africa: key areas for policy intervention. United Nations Industrial Development Organization Private Sector Development Branch.

Ariyo, D. (2007). "Small firms are the backbone of the Nigerian economy". www.AfricaEconomicAnalysis.org. Last assessed:

Arthur, J. B. (1994). "Effects of human resource systems on manufacturing performance and turnover". Academy of Management Journal, 37, 670-687.

Bacon, N. \& Hoque, K. (2005). "HRM in the SME sector: valuable employees and coercive networks". International Journal of Human Resource Management, 16, 1976-1999.

Barney, J. B. \& Wright, P. M. (1998). “On becoming a strategic partner: The role of human resources in gaining competitive advantage”. Human Resource Management, 37, 31-46.

Baird, L., \& Meshoulam, I. (1988). "Managing two fits of strategic human resource management”. Academy of Management Review, 13, 116 - 128.

Barney, J. (1991). “Firm resources and sustained competitive advantage”. Journal of Management, 17, 99-120.

Boselie, P., Paauwe, J. \& Richardson, R. (2003). "Human resource management, institutionalization and organizational performance: a comparison of hospitals, hotels and local government”. International Journal of Human Resource Management, 14, 1407-1429.

Ciavarella, M. A. (2003). "The Adoption of high-involvement practices and processes in emergent and developing firms: A descriptive and prescriptive approach”. Human Resource Management, 42, 337-356.

Delaney, J. T. \& Huselid, M. A. (1996). "The impact of human resource management practices on perceptions of organizational performance”. Academy of Management Journal 39, 949-969.

DiMaggio, P. \& Powell, W. (1983). "The iron cage revisited: institutional isomorphism and collective rationality in organizational fields’”, American Sociological Review, 48: 147-60.

Duberley, J. P. \& Walley, P. (1995). "Assessing the adoption of HRM by small and medium-sized manufacturing organizations”. International Journal of Human Resource Management, 6, 891-909.

Foreman-Peck, J., Makepeace, G \& Morgan, B. (2006). "Growth and profitability of small and medium-sized enterprises: Some welsh evidence.” Regional Studies, 40, 307-319

Guest, D.E., Michie, J., Conway, N. \& Sheehan, M. (2003). "Human resource management and corporate performance in the UK”. British Journal of Industrial Relations, 41, 291-314.

Harney, B. \& Dundon, T. (2006). Capturing complexity: developing an integrated approach to analyzing HRM in SMEs. Human Resource Management Journal, 16, 48-73.

Hayton, J.C. (2003). "Strategic human capital management in SMEs: An empirical study of entrepreneurial performance”. Human Resource Management, 42, 375-391. 
Heneman, R. L., Tansky, J. W. \& Camp, S. M. (2000). "Human resource management practices in small and medium-sized enterprises: Unanswered questions and future research perspectives.” Entrepreneurship: Theory \& Practice, 25, 11-25.

Heneman. R. E., \& Tansky, J. (2002). "Human resource management models for entrepreneurial opportunity: Existing knowledge and New Directions”. In J. A. Katz \& T. M. Welbourne (Eds.), Advances in entrepreneurship, firm emergence and growth, (Vol. 5 pp. 55 -81). Greenwich, CT: JAI Press Inc.

Huselid, M. A. (1995). “The impact of human resource management practices on turnover, productivity and corporate financial performance”. Academy of Management Journal, 38, 635-672.

Jones, G. and Wright, P. (1992). “An economic approach to conceptualizing the utility of human resource management practices”. In K. Rowland and G. Ferris (Eds.), Research in Personnel and Human Resource Management, (pp. 271-299).

Judge, W. Q., Douglas, T. J. \& Kutan, A. M. (2008). “Institutional antecedents of corporate governance legitimacy.” Journal of Management, 34, 765 - 785.

Kamoche, K. (1997). "Managing Human Resources in Africa: Strategic, Organizational and Epistemological Issues”. International Business Review, 7, 537-558.

Kaufman, H. (1975). “The natural history of human organizations”. Administration \& Society, 7, 131-149.

Kauffmann, C. 2005. "Financing SMEs in Africa." Policy Insights, 7.

http://www.oecd.org/dataoecd/57/59/34908457.pdf. Assessed: December, 2007.

Kotey, B. \& Slade, P. (2005). “Formal human resource management practices in small growing firms”. Journal of Small Business Management, 43, 16-40.

Luetkenhorst, W. (2004). “Corporate Social Responsibility (CSR) and the Development Agenda: Should SMEs Care”. SME Technical Working Paper Series, 13. Vienna: United Nations Industrial Development Organization.

MacDuffie, J. (1995). "Human resource bundles and manufacturing performance: Organizational logic and flexible production systems in the world auto industry”. Industrial and Labor Relations Review, 48, 197-221.

Mambula, C. (2002). "Perceptions of SME growth constraint in Nigeria”. Journal of Small Business Management, 40, 58-65.

Meyer, J. W. \& Rowan, B. (1977). "Institutionalized Organizations: Formal structure as myth and ceremony”. American Journal of Sociology, 83, 340-63.

Miles, R. \& Snow, C. (1984). “Designing Strategic Human Resource Systems”. Organizational Dynamics, 2 , 36-52.

Newberry, D. (2006). The role of small- and medium-sized enterprises in the futures of emerging economies. World Resource Institute.

OECD. (2004) Promoting entrepreneurship and innovative SMEs in a global economy: towards a more responsible and inclusive globalization. 2nd OECD conference of ministers responsible for small and medium-sized enterprises (SMEs). (pp.1-59). Istanbul, Turkey: Organization for economic cooperation and development.

Onyiewu, S. (1993). “Graduation problems amongst micro and small enterprises in eastern Nigeria, 1960-91”. Journal of International Development, 5, 497-510.

Paauwe, J., \& Boselie, P. 2003. “Challenging 'strategic HRM' and the relevance of the institutional setting”. Human Resource Management Journal, 13, 56-70. 
Pfeffer, J. (1994). Competitive Advantage through People. Boston: MA: Harvard Business School Press.

Pfeffer, J., \& Salancik, G. R. (1978). The external control of organizations: A resource dependence perspective. New York: Harper \& Row.

Powell, W. \& DiMaggio, P. (1991). The new institutionalism in organizational analysis. Chicago and London. The University of Chicago Press.

Purcell, J. (1993). "Developing research in comparative HRM". International Journal of Human Resource Management, 4, 507-510.

Quinn, R. E. \& Cameron, K. (1983). "Organizational life cycles and shifting criteria of effectiveness: Some preliminary evidence”. Management Science 29, 33-51.

Rutherford, M., Buller, P. F. \& McMullen, P. R. (2003). "Human resource management problems over the life cycle of small to medium-sized firms”. Human Resource Management, 42, 321-335.

Scott, W. R. \& Davis, G. (2007). Organizations and organizing: rational, natural and open system perspectives. Prentice Hall, New Jersey.

Subramony, M. (2006). "Why organizations adopt some human resource practices and reject others". Human Resource Management. 25, 195-210.

Tansky, J. W. \& Heneman, R. (2003) .Guest Editor's Note: Introduction to the special issue on human resource management in SMEs: A call for more research. Human Resource Management, 42, 299-302.

Utomi, P. (1997). Managing uncertainty: competition and strategy in emerging economies. Ibadan: Spectrum books.

Wright, P.M. \& MacMahon, G.C. (1992). "Alternative Theoretical Perspectives for Strategic Human Resource Management”. Journal of Management, 18, 295-320.

Wagar, T. (1998). "Determinants of Human Resource Management Practices in Small Firms: Some Evidence from Atlantic Canada”. Journal of Small Business Management, 36, 13-23.

Zucker, L. (1977). “The role of institutionalization in cultural persistence”. American Sociological Review, 42, 726743. 